\title{
XMRV: Usage of Receptors and potential Co-receptors
}

\author{
Mohan Kumar Haleyur Giri Setty, Krishnakumar Devadas, Viswanath Ragupathy, Veerasamy Ravichandran, \\ Shixing Tang, Owen Wood, Durga Sivacharan Gaddam, Sherwin Lee and Indira K Hewlett
}

\begin{abstract}
Background: XMRV is a gammaretrovirus first identified in prostate tissues of Prostate Cancer (PC) patients and later in the blood cells of patients with Chronic Fatigue Syndrome (CFS). Although XMRV is thought to use XPR1 for cell entry, it infects A549 cells that do not express XPR1, suggesting usage of other receptors or co-receptors.

Methods: To study the usage of different receptors and co- receptors that could play a role in XMRV infection of lymphoid cells and GHOST (GFP- Human osteosarcoma) cells expressing CD4 along with different chemokine receptors including CCR1, CCR2, etc., were infected with XMRV. Culture supernatants and cells were tested for XMRV replication using real time quantitative PCR.

Results: Infection and replication of XMRV was seen in a variety of GHOST cells, LNCaP, DU145, A549 and Caski cell lines. The levels of XMRV replication varied in different cell lines showing differential replication in different cell lines. However, replication in A549 which lacks XPR1 expression was relatively higher than DU145 but lower than, LNCaP. XMRV replication varied in GHOST cell lines expressing CD4 and each of the co- receptors CCR1-CCR8 and bob. There was significant replication of XMRV in CCR3 and Bonzo although it is much lower when compared to DU145, A549 and LNCaP.

Conclusion: XMRV replication was observed in GHOST cells that express CD4 and each of the chemokine receptors ranging from CCR1- CCR8 and BOB suggesting that infectivity in hematopoietic cells could be mediated by use of these receptors.
\end{abstract}

\section{Introduction}

A new gamma retrovirus, Xenotropic Murine leukaemia Virus-related virus (XMRV), was identified in 2006 and its association was claimed with prostate cancer (PC) and chronic fatigue syndrome (CFS). A series of studies from disparate geographical areas have failed to substantiate these claims. Recent studies have suggested that XMRV may have arisen in mice through recombination of two proviruses [1].

Regardless of the controversies, XMRV is a culturable virus capable of infecting different cell types like $\mathrm{T}$ and B Lymphocytes, NK cells, etc., [2]. Intravenous inoculation of Rhesus Macaques with XMRV showed organspecific cell tropism, infecting CD4 T cells in lymphoid organs including the gastrointestinal lamina propria,

\footnotetext{
* Correspondence: indira.hewlett@fda.hhs.gov

* Correspondence: indira.hewlett@fda.hhs.gov Bethesda, MD 20892, USA
}

() 2011 Haleyur Giri Setty et al; licensee BioMed Central Ltd. This is an Open Access article distributed under the terms of the Creative

alveolar macrophages in lung, and epithelial/interstitial cells in other organs, and cells of the reproductive tract [3]. Many retroviruses are pathogenic (HIV-1) causing severe disease but at the same time they have been used in gene therapy which requires targeting of the virus to the host cell through interactions between viral envelope proteins and cell surface proteins. It is important to determine the mode of its cell entry to define tropism, and understand virus transmission and pathogenesis. Biological process involves highly specific interactions and infection of cells by viruses is no exception. Such interactions are of major importance in pathogenic viruses as they are potential drug targets. One such classic example is the entry of HIV-1 through a series of interactions between the viral gp120 and cellular receptor CD4 and co-receptor such as either CCR5 or CXCR5 [4].

The xenotropic/polytropic subgroup of mouse leukemia viruses (MLVs) all rely on the XPR1 receptor for 
entry, but these viruses vary in tropism, distribution among wild and laboratory mice, pathogenicity, strategies used for transmission, and sensitivity to host restriction factors [5]. XMRV is closely related to xenotropic murine leukemia viruses MLVs (X-MLVs) [6]. The X-MLVs and polytropic MLVs (P-MLV) use Xpr1 as a receptor for cell entry $[4,7,8]$, and so does XMRV [9-11]. The recent identification of MLV and XMRV in human prostate cancer tissues, peripheral blood mononuclear cells (PBMCs) of chronic fatigue syndrome patients, and the respiratory tract of immunocompromised patients [12] raises the concern of a potential threat to public health from cross-species transmission of MLV related viruses.

\section{Results and discussion}

Infection and replication of XMRV was observed in a variety of GHOST cells, LNCaP, DU145, A549 and CaSki cell lines (Figure 1 and 2). The levels of XMRV replication varied in different cell lines. However, replication in A549 which lacks XPR1 expression was relatively high compared with DU145 but lower than levels observed in LNCaP (Figure 1C and 2C). These findings suggest that perhaps other molecules could serve as receptors for this virus in addition to Xpr1. XMRV replicated less efficiently in GHOST cell lines expressing CD4 and each of the co- receptors CCR1 - CCR8 and Bob compared with A549 and LNCaP. However, among the GHOST cell lines there was significant replication of $\mathrm{XMRV}$ in CCR3 and Bonzo expressing cells (Figure 1C and $2 \mathrm{C}$ ).

XMRV infection of GHOST cells that express CD4 and each of the chemokine receptors ranging from CCR1- CCR8 and Bob suggests that infection and tropism for hematopoietic cells could be mediated by use of these receptors as XPR1 is not expressed in blood cells and very weakly expressed in bone marrow (Gene Atlas). Replication of XMRV in A549 cells lacking XPR1 was much higher when compared with DU145 which express XPR1. Furthermore, the cell line 293T expresses XPR1 but did not support XMRV replication. These findings clearly indicate the possibility of other receptors for XMRV than XPR1. Interestingly CCR1, CCR2, and CCR3 are expressed in A549 and Bonzo in PC-3, DU145, LNCaP and A549 [13,14]. More research may be needed to fully understand the scope and extent to

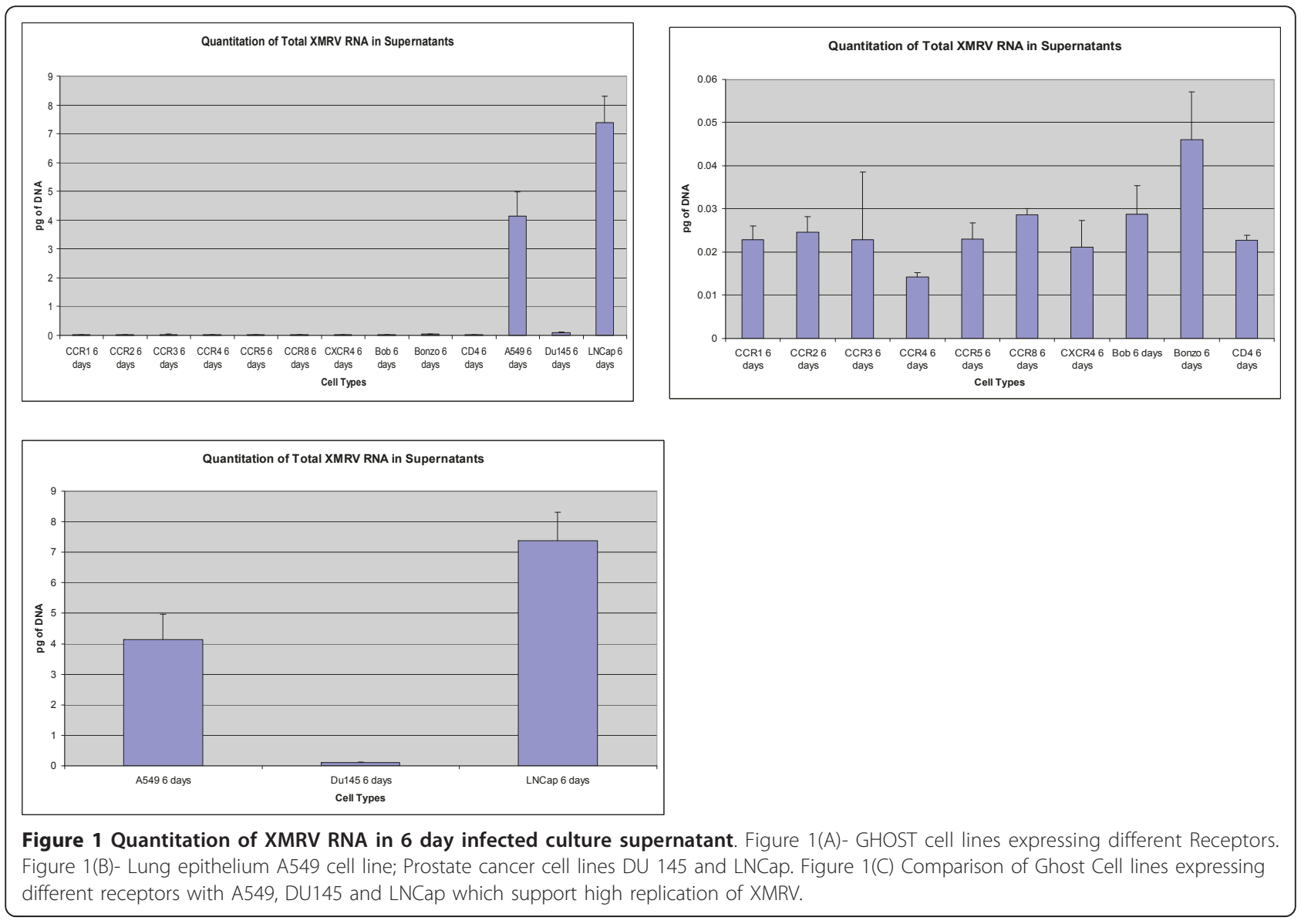




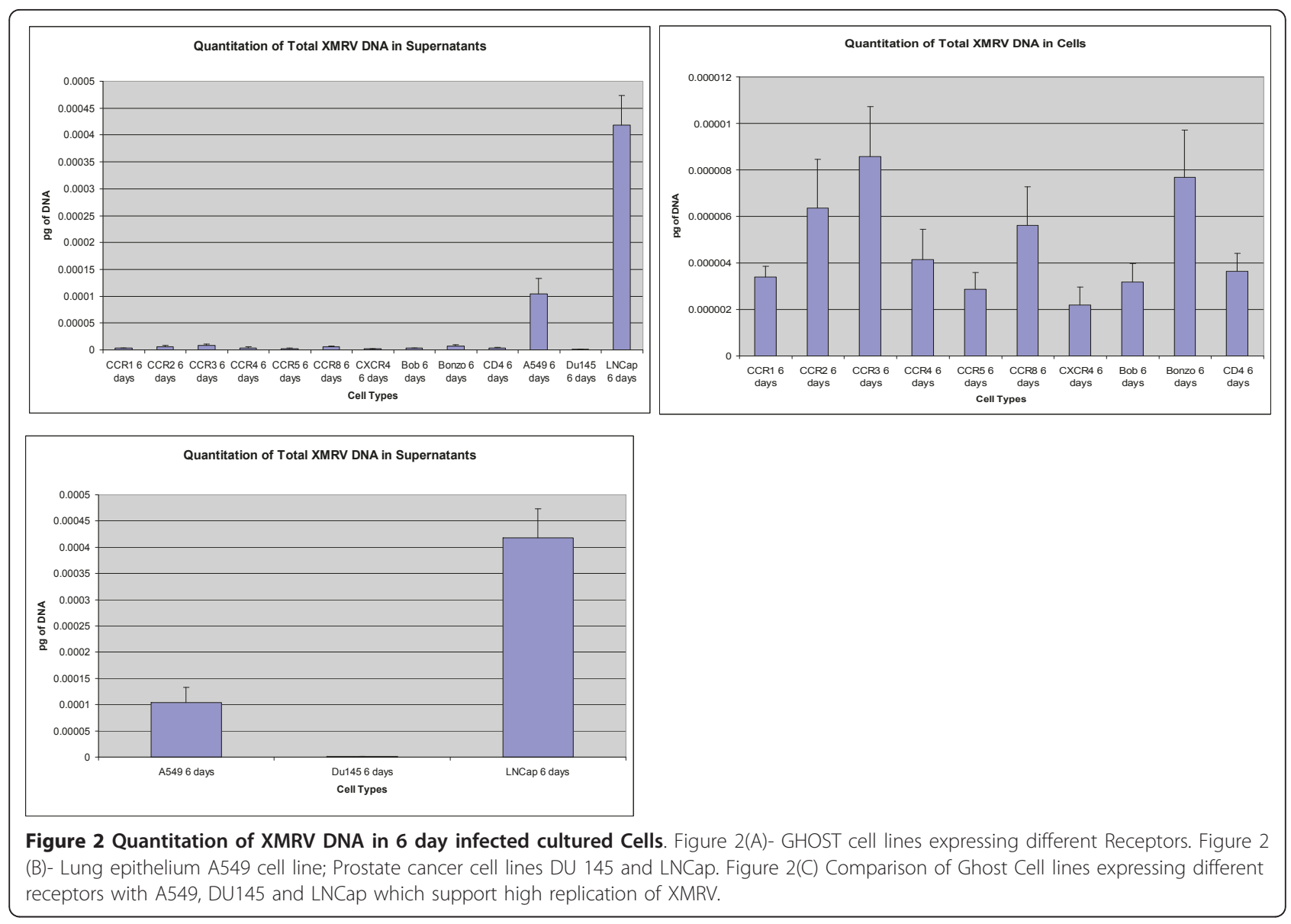

which this mouse derived virus uses other receptors to enter human cells and cross species susceptibility in line with its xenotropic nature.

\section{Materials and methods \\ Cells}

GHOST (GFP- Human osteosarcoma) cells expressing CD4 along with different chemokine receptors including CCR1, CCR2, etc., were grown in Dulbecco's modified Eagle's medium (DMEM Quality Biologics) with 10\% fetal bovine serum (FBS).

\section{XMRV infectivity in various cell types}

After three and six days of infection the XMRV levels in supernatant and the integrated viral DNA in cells were quantified using real time quantitative PCR. The values were normalized by taking equal amounts of RNA/DNA and compared with XMRV clone VP62-pcDNA3.1 standard (GenBank accession no. EF185282; obtained through NIH AIDS Research and Reference Reagent Program).

\section{RNA isolation}

Total RNA and DNA were isolated using Qiagen extraction kits.

\section{Quantitative PCR}

An equal amount of total RNA was used to quantify XMRV levels using QuantiTect Probe RT-PCR kit (Qiagen). Real-time PCR Master Mix (Quantitect Probe RTPCR, Qiagen) was added with forward and reverse primers, probe, and cDNA or RNA in a total volume of 25 uL. Real-time PCR from RNA was done with the same contents as above in addition to RT-mix (Qiagen) and primer for Viral RNA. The mixture was incubated at $50^{\circ}$ $\mathrm{C}$ for $2 \mathrm{~min}$ (for RNA, $20 \mathrm{~min}$ ), at $95^{\circ} \mathrm{C}$ for $10 \mathrm{~min}$, and then cycled at $95^{\circ} \mathrm{C}$ for $15 \mathrm{sec}$ and $60^{\circ} \mathrm{C}$ for $60 \mathrm{sec} 40$ times, using the Applied Biosystems 7500 sequence detection system.

\section{Acknowledgements}

We thank NIH AIDS Reagent Program for Ghost cell lines. We thank Dr. Xue Wang, Dr. Mingjie Zhang, Dr. Robin Biswas, and Dr. Chintamani D. Atreya for critical review of the article. This work was supported by funds from CPATH 
FDA. The findings and conclusions in this paper have not been formally disseminated by the Food and Drug Administration and should not be construed to represent any Agency determination or policy.

\section{Authors' contributions}

All authors read and approved the final manuscript. $\mathrm{MH}$ performed experiments; $\mathrm{MH}, \mathrm{IKH}$ and $\mathrm{KD}$ contributed to designing research, analyzing data, discussing findings, and writing the manuscript; KD, SL and OW virus culture and propagation; ST virus copy number determination; ST, VR, DSG and VR contributed to Real-time PCR primer design and assay standardization; OW and VR GHOST cell culture and propagation. IKH supervised the work.

\section{Competing interests}

The authors declare that they have no competing interests.

Received: 12 July 2011 Accepted: 6 September 2011

Published: 6 September 2011

\section{References}

1. Paprotka Tobias, Delviks-Frankenberry AKrista, Cingöz Oya, Martinez Anthony, Kung HsingJien, Tepper GClifford, Hu Wei-Shau, Fivash JMatthew Jr, Coffin MJohn, Vinay K: Pathak Recombinant Origin of the Retrovirus XMRV. Science 2011, 333:97-101.

2. Qiu Xiaoxing, Swanson Priscilla, Luk Ka-Cheung, Tu Bailin, Villinger Francois, Das Gupta Jaydip, Silverman HRobert, Klein AEric, Devare Sushil, Schochetman Gerald, Hackett John Jr: Characterization of antibodies elicited by XMRV infection and development of Immunoassays useful for epidemiologic studies. Retrovirology 2010, 7:68.

3. Onlamoon N, Das Gupta J, Sharma P, Rogers K, Suppiah S, Rhea J, Molinaro RJ, Gaughan C, Dong B, Klein EA, Qiu X, Devare S,

Schochetman G, Hackett J Jr, Silverman RH, Villinger F: Infection, Viral Dissemination, and Antibody Responses of Rhesus Macaques Exposed to the Human Gammaretrovirus XMRV. J Virol 2011, 85(9):4547-57.

4. D'Souza MP, Harden VA: Chemokines and HIV-1 second receptors. Confluence of two fields generates optimism in AIDS research. Nat Med 1996, 2:1293-300.

5. Kozak CA: The mouse "xenotropic" gammaretroviruses and their XPR1 receptor. Retrovirology 2010, 7:101.

6. Urisman A, Molinaro RJ, Fischer N, Plummer SJ, Casey G, Klein EA, Malathi K, Magi-Galluzzi C, Tubbs RR, Ganem D, Silverman RH, DeRisi JL: Identification of a novel Gammaretrovirus in prostate tumors of patients homozygous for R462Q RNASEL variant. PLoS Pathog 2006, 2:e25.

7. Tailor CS, Nouri A, Lee CG, Kozak C, Kabat D: Cloning and characterization of a cell surface receptor for xenotropic and polytropicmurine leukemia viruses. Proc Natl Acad Sci USA 1999, 96:927-932.

8. Yang YL, Guo L, Xu S, Holland CA, Kitamura T, Hunter K, Cunningham JM: Receptors for polytropic and xenotropic mouse leukaemia viruses encoded by a single gene at Rmc1. Nat Genet 1999, 21:216-219.

9. Dong B, Kim S, Hong S, Das Gupta J, Malathi K, Klein EA, Ganem D, Derisi JL, Chow SA, Silverman RH: An infectious retrovirus susceptible to an IFN antiviral pathway from human prostate tumors. Proc Natl Acad Sci USA 2007, 104:1655-1660.

10. Knouf EC, Metzger MJ, Mitchell PS, Arroyo JD, Chevillet JR, Tewari M, Miller AD: Multiple integrated copies and high-level production of the human retrovirus XMRV (xenotropic murine leukemia virus relate virus) from 22Rv1 prostate carcinoma cells. J Virol 2009, 83:7353-7356.

11. Yan Y, Liu Q, Kozak CA: Six host-range variants of the xenotropic/ polytropic gammaretroviruses define determinants for entry in the XPR1 cell surface receptor. Retrovirology 2009, 6:87.

12. Fischer N, Schulz C, Stieler K, Hohn O, Lange C, Drosten C, Aepfelbacher M: Xenotropic murine leukemia virus-related gammaretrovirus in respiratory tract. Emerg Infect Dis 2010, 16(6):1000-2.
13. HongKoo Ha, Lee Wan, Jun Park Hyun, Lee SangDon, JeongZoo Lee, Kee Chung Moon: Clinical significance of CXCL16/CXCR6 expression in patients with prostate cancer. Molecular Medicine Reports 2011, 4:419-424.

14. Lu Yi, Wang Jianhua, Xu Yang, Koch EAlisa, Zhong Cai1, Chen Xue, Galson LDeborah, Russell S, Taichman, Jian Zhang: CXCL16 Functions as a Novel Chemotactic Factor for Prostate Cancer Cells In vitro. Mol Cancer Res 2008, 546.

doi:10.1186/1743-422X-8-423

Cite this article as: Haleyur Giri Setty et al:: XMRV: Usage of Receptors and potential Co-receptors. Virology Journal 2011 8:423.

\section{Submit your next manuscript to BioMed Central and take full advantage of:}

- Convenient online submission

- Thorough peer review

- No space constraints or color figure charges

- Immediate publication on acceptance

- Inclusion in PubMed, CAS, Scopus and Google Scholar

- Research which is freely available for redistribution

Submit your manuscript at www.biomedcentral.com/submit
Biomed Central 